\title{
Controllability and Persistence of Money Market Rates along the Yield Curve: Evidence from the Euro Area
}

\author{
Ulrike Busch* \\ Dieter Nautz**
}

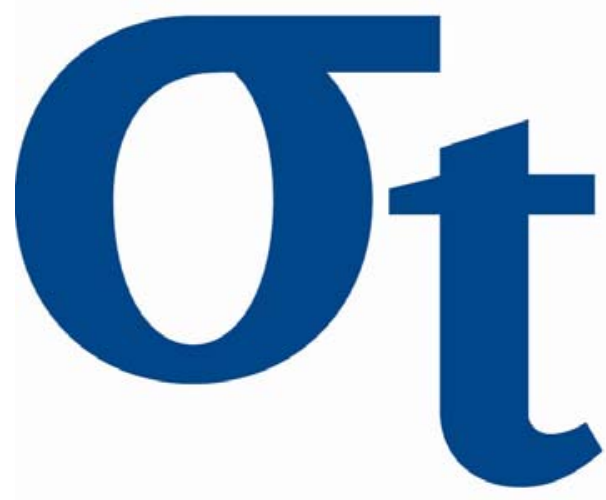

9)

寸

6

* Goethe-Universität Frankfurt, Germany

** Freie Universität Berlin, Germany 


\title{
Controllability and Persistence of Money Market Rates along the Yield Curve: Evidence from the Euro Area
}

\author{
Ulrike Busch* \\ Goethe University Frankfurt
}

\author{
Dieter Nautz ${ }^{\dagger}$ \\ Free University Berlin
}

May 13, 2009

\begin{abstract}
Controllability of longer-term interest rates requires that the persistence of their deviations from the central bank's policy rate (i.e. the policy spreads) remains sufficiently low. This paper applies fractional integration techniques to assess the persistence of policy spreads of euro area money market rates along the yield curve. Independently from anticipated policy rate changes, there is strong evidence for all maturities that policy spreads exhibit long memory. We show that recent changes in the operational framework and the communication strategy of the European Central Bank have significantly decreased the persistence of euro area policy spreads and, thus, have enhanced the central bank's influence on longer-term money market rates.

Keywords: Long memory and fractional integration; controllability and persistence of interest rates; new operational framework of the ECB
\end{abstract}

JEL classification: C22, E43, E52

\footnotetext{
${ }^{*}$ We thank Uwe Hassler, Barbara Meller, Maya Olivares, Jan Scheithauer, Alexander Schulz, participants of the 2008 annual meetings of the Econometrics research committee of the Verein fuer Socialpolitik and the European Economic Association in Milan, and two anonymous referees for very helpful comments and suggestions. This research was supported by the Deutsche Forschungsgemeinschaft through the CRC 649 "Economic Risk". E-mail: ubusch@wiwi.uni-frankfurt.de

${ }^{\dagger}$ Email: dieter.nautz@fu-berlin.de.
} 


\section{Introduction}

Longer-term interest rates are essential channels for the transmission of monetary policy. A reliable link between longer-term rates and the central bank's key policy rate is therefore of crucial importance. ${ }^{1}$ By managing market's expectations of the future path of interest rates, central banks ensure that policy spreads, i.e. the deviations of market rates from the policy rate, are small and that their volatilities remain well contained. In this paper we argue that monetary policy should also be concerned about the persistence of interest rates. Because if policy spreads are too persistent, the lasting impact of shocks would impede the transparency of policy signals and the central bank's impact on longer-term rates. The first contribution of the paper is, therefore, to investigate the persistence of policy spreads of euro area money market rates to shed more light on the controllability of interest rates along the yield curve.

The persistence of policy spreads should also be related to the effectiveness of monetary policy. For example, unclear policy signals about future interest rate decisions should lead to larger forecast errors and more persistent policy spreads. In line with the recent literature on the relation between monetary policy and the persistence of inflation, our second contribution is to investigate whether the persistence of longer-term rates depends on the predictability and communication of monetary policy $!^{2}$ In March 2004, the ECB improved its communication strategy and its operational framework for monetary policy implementation, see European Central Bank (2004). We will use this reform as a natural experiment to test for the influence of institutional changes on the persistence of euro area money market interest rates along the yield curve.

According to Balduzzi et al. (1998), the persistence of U.S. policy spreads increases with the maturity of the underlying money market rate implying a diminishing controllability of interest rates along the yield curve. Assum-

\footnotetext{
${ }^{1}$ Central banks increasingly use key policy rates or interest rate targets for the overnight rate to signal the monetary policy stance. Examples are the Fed's target for the Federal Funds Rate and the ECB's minimum bid rate preannounced in its weekly main refinancing operations.

${ }^{2}$ There is increasing evidence that inflation persistence in the euro area and the United States has actually been reduced over the last decade. It is less clear, however, whether this reduction is a consequence of better monetary policy, see e.g. Kumar and Okimoto (2007).
} 
ing that policy spreads are integrated of order zero $(\mathrm{I}(0))$, they estimate persistence by means of standard autocorrelation functions. This approach, however, can lead to biased results if the policy spread is not $\mathrm{I}(0)$ but exhibits long memory. In fact, Hassler and Nautz (2008) and Cassola (2007) find that even the spread between the overnight rate and the ECB's policy rate is fractionally integrated of order $d \approx 0.25$. Restricting their attention to the overnight rate, both papers suggest that the ECB's impact on interest rates might be weaker than expected $3^{3}$

The paper is organized as follows. Section 2 describes the data, discusses the role of rate change expectations for the behavior of policy spreads along the money market yield curve, and introduces an expectations-adjusted policy spread based on Eonia swap rates. Section 3 briefly recalls the fractional integration approach for measuring persistence and presents first empirical results on the policy spread persistence for the whole sample period. Section 4 sheds more light on the relation between policy spread persistence and monetary policy implementation. In particular, we investigate whether the recent reform in the ECB's operational framework has influenced the persistence of policy spreads. Section 5 summarizes the main results and concludes.

\section{Policy Spreads and Interest Rate Expec- tations}

\subsection{Data}

Our empirical analysis is based on daily data of euro area money market rates (Euribor) with 14 different maturities ranging from 1 week up to 12 months. For each maturity, the corresponding policy spread is defined as the difference between the market rate and the ECB's key interest rate, i.e. the minimum bid rate of the main refinancing operations (MROs). The sample starts at June 27, 2000, when the minimum bid rate was introduced and it ends on July 30, 2007. Our sample does not include interest data affected by the liquidity crisis starting in early August 2007. Since then,

\footnotetext{
${ }^{3}$ There is a growing literature on the persistence of macroeconomic and financial time series rejecting the dichotomy of $\mathrm{I}(0)$ versus $\mathrm{I}(1)$ processes in favor of fractional orders of integration. Recent examples include contributions on the changing persistence of inflation (Kumar and Okimoto (2007)) and GDP and unemployment (Gil-Alana (2002)).
} 
policy spreads between the unsecured Euribor rates and the minimum bid rate have widened dramatically due to sharply increased liquidity risk. Empirical models of the European overnight rate (Eonia) have to account for marked calendar effects including the large peaks and troughs at the end of the reserve maintenance period, see e.g. Nautz and Offermanns (2008). For Euribor rates in contrast, a particular adjustment is not required since calendar effects play only a minor role for longer-term rates.

Figure 1: Euribor (1 month), minimum bid rate, and policy spread

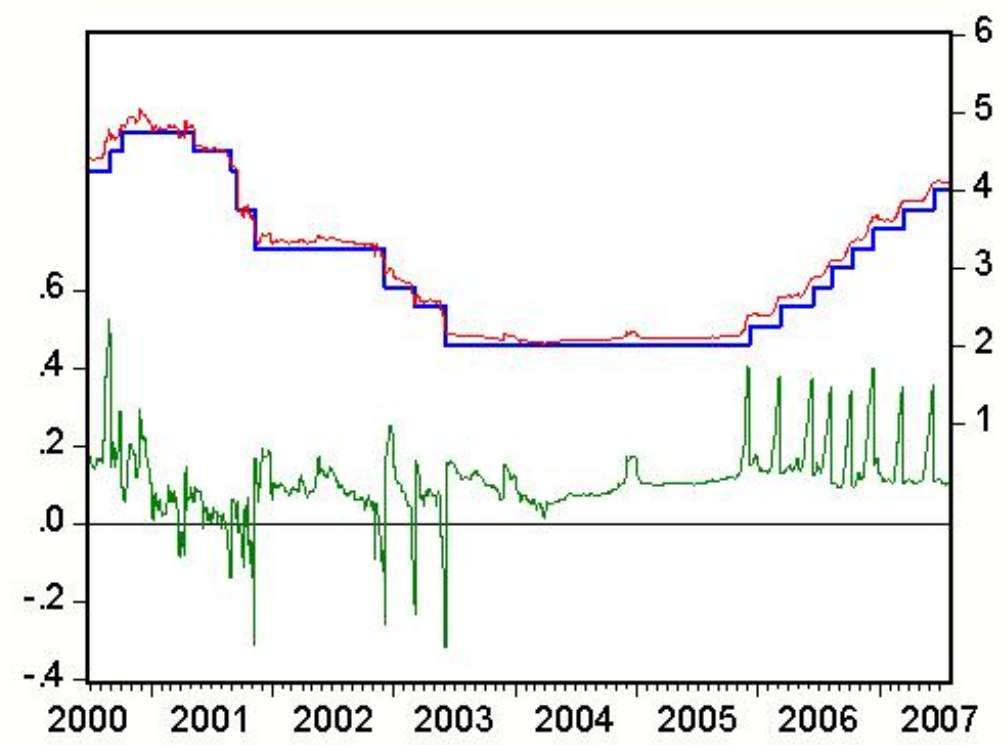

Right scale: Euribor (1 month) and minimum bid rate (bold line) in percentage points. Left scale: Spread between Euribor and minimum bid rate (policy spread) in percentage points.

Figure 1 displays exemplarily the 1-month Euribor and the ECB's minimum bid rate together with the resulting policy spread. At first sight, the Euribor follows the policy rate rather closely. However, there are also longer periods of persistent deviations where the policy spread increased steadily even though the minimum bid rate stayed constant. Some but not all of these movements in the policy spread can be explained ex post by prospective changes of the policy rate. In particular, since 2005 correctly anticipated interest rate decisions of the ECB have led repeatedly to persistent deviations of the Euribor from the current policy rate starting exactly one month before the policy rate actually changed. In this case, persis- 
tent deviations of the market rate from the current policy rate are a direct consequence of the central bank's clear communication of the future policy stance and do not indicate a loss of the central bank's control over money market rates. In the following, we account for the effect of interest rate expectations by constructing an expectations-adjusted policy spread based on Eonia swap rates.

\subsection{Interest Rate Expectations and OIS Spreads}

In the euro area, market's expectations on future policy rates are reflected in the Eonia swap market, where swap contracts with all Euribor maturities are traded to speculate on and hedge against future interest rate movements. The Eonia swap market is one of the most important derivative market segments in the euro area, see e.g. Durré (2007). The swap contract involves two parties, one paying a fixed rate (the swap rate) and one paying a variable rate (the average Eonia over the maturity of the swap). Therefore, Eonia swap rates, $O I S_{t}(k)$, are natural proxy variables for market's expectations in period $t$ of the average Eonia $\left(\frac{1}{k} \sum_{i=0}^{k-1} E_{t} r_{t+i}\right)$ and, thereby, of the average policy rate over the swap's duration $(k)$ :

$$
O I S_{t}(k) \approx \frac{1}{k} \sum_{i=0}^{k-1} E_{t} r_{t+i}
$$

More precisely, the swap rate can be interpreted as the average short-term rate that the market expects to prevail for the next $k$ days in the absence of risk and liquidity considerations. All deviations of the Euribor rate from the current policy rate which are due to anticipated future policy rate changes must be revealed in the swap rate. Therefore, subtracting the swap rate $O I S_{t}(k)$ from the corresponding Euribor $r_{t}(k)$ leads to the OIS spread which can be interpreted as the expectations-adjusted policy spread,

$$
O I \operatorname{Sspread}_{t}(k)=r_{t}(k)-O I S_{t}(k) \text {. }
$$

If the policy rate $r_{t}^{*}$ is expected to be constant over the swap's maturity $(k), O I S_{t}(k)$ will be very close to $r_{t}^{*}$ and $O I S s p r e a d_{t}(k)$ will coincide with the unadjusted policy spread $r_{t}(k)-r_{t}^{*}$. According to Taylor and Williams (2009), OIS spreads are the most reliable measure of expectations-adjusted policy spreads. During the recent financial turmoil, OIS spreads have been 
increasingly used to assess the unusual behavior of longer term money market rates.

Figure 2: Minimum bid rate and OIS spread

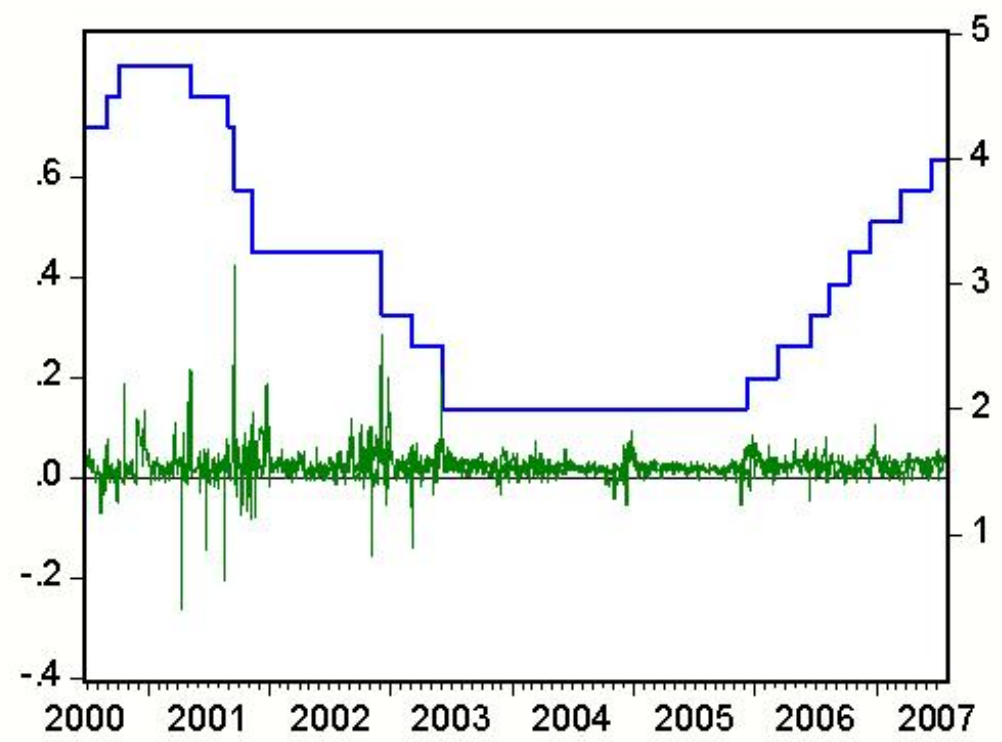

Right scale: Minimum bid rate (bold line) in percentage points. Left scale: OIS spread defined as spread between Euribor 1 month and Eonia swap rate 1 month (expectationsadjusted policy spread) in percentage points.

Figure 2 shows the one-month OIS spread, i.e. the policy spread adjusted for expected changes of the policy rate revealed by the one-month Eonia swap rate. Note that the OIS spread does not display the large expectation-driven peaks of its unadjusted counterpart, compare Figure 1 . Similar results are obtained for OIS spreads for all 14 maturities under consideration.

Similar to the findings of Balduzzi et al. (1998) obtained for U.S. data, mean and standard deviation of unadjusted policy spreads in the euro area increase almost linearly with the maturity of the money market rate 4 At first sight, this indicates that the influence of the central bank on interest rates weakens with their maturity. However, the corresponding OIS spreads reveal that this is not necessarily true. For all maturities, expectationsadjustment has not only significantly decreased the mean and the standard

\footnotetext{
${ }^{4}$ For brevity, descriptive statistics are not shown but are available on request from the authors.
} 
deviation of policy spreads. Both, mean and standard deviation of OIS spreads remain also nearly constant along the yield curve.

\subsection{Unit Root Tests}

Stationarity and persistence of interest rates is usually examined by means of standard unit root tests, as the ADF-test, where the null hypothesis "the interest rate is $\mathrm{I}(1)$ " is tested against the alternative that it is $\mathrm{I}(0)$. Alternatively, KPSS-tests can be used where null and alternative hypotheses are reversed. We applied both types of tests to our set of 14 OIS spreads.

Table 1: Unit root tests for OIS spreads

\begin{tabular}{llc}
\hline \hline Maturity & ADF: $H_{0}=I(1)$ & KPSS: $H_{0}=I(0)$ \\
\hline $1 \mathrm{w}$ & $-22.09^{* * *}$ & $0.41^{*}$ \\
$2 \mathrm{w}$ & $-14.34^{* * *}$ & $0.47^{* *}$ \\
$1 \mathrm{~m}$ & $-12.95^{* * *}$ & 0.15 \\
$2 \mathrm{~m}$ & $-10.37^{* * *}$ & 0.34 \\
$3 \mathrm{~m}$ & $-7.54^{* * *}$ & $0.54^{* *}$ \\
$4 \mathrm{~m}$ & $-9.25^{* * *}$ & $0.61^{* *}$ \\
$5 \mathrm{~m}$ & $-8.74^{* * *}$ & $0.76^{* * *}$ \\
$6 \mathrm{~m}$ & $-7.84^{* * *}$ & $0.59^{* *}$ \\
$7 \mathrm{~m}$ & $-6.50^{* * *}$ & $0.79^{* * *}$ \\
$8 \mathrm{~m}$ & $-5.79^{* * *}$ & $0.87^{* * *}$ \\
$9 \mathrm{~m}$ & $-9.09^{* * *}$ & $0.74^{* * *}$ \\
$10 \mathrm{~m}$ & $-7.52^{* * *}$ & $0.73^{* *}$ \\
$11 \mathrm{~m}$ & $-8.35^{* * *}$ & $0.67^{* *}$ \\
$12 \mathrm{~m}$ & $-19.82^{* * *}$ & $0.38^{*}$ \\
\hline \hline
\end{tabular}

Notes: Spread between Euribor and Eonia swap rate of the corresponding maturity for June 27, 2000 - July 30, 2007 (OIS spreads). For the ADF-test t-statistics and for the KPSS-test LM-statistics are given. Stars denote significance at the $1 \%, 5 \%$ and $10 \%$ significance level $(* * *, * *, *)$. The lag length for the ADF-test (with constant) is chosen according to the Schwarz-information criterion and the bandwidth choice for the KPSS-test follows the Newey-West criterion using a Bartlett kernel.

According to Table 1 the ADF-tests uniformly suggest that policy spreads are $\mathrm{I}(0)$, this hypothesis is strongly rejected by the KPSS-tests for most ma- 
turities. Apparently, modeling the persistence of European policy spreads in the $\mathrm{I}(0) / \mathrm{I}(1)$ dichotomy is too restrictive. In the remainder of the paper, we therefore allow for a fractional order of integration $0 \leq d \leq 1$ as a more general measure for the persistence of a time series.

The empirical literature on overnight rate dynamics typically assumes that the corresponding policy spread is $\mathrm{I}(0)$, see e.g. Pérez Quirós and Rodríguez Mendizábal (2006) and Nautz and Offermanns (2007). For the euro area, this assumption has been challenged by recent empirical evidence. Cassola (2007) as well as Hassler and Nautz (2008) found the Eonia spread, i.e. the ECB's policy spread with respect to the overnight rate, to be fractionally integrated with $d \approx 0.25$. Similar results are obtained for various euro area interest rates of one week maturity, see Cassola and Morana (2008). Following this line of research, we apply fractional integration techniques to estimate the persistence of policy spreads along the money market yield curve. Before doing so, let us briefly recall the distinguishing features of fractionally integrated, long memory processes.

\section{Fractional Integration and the Persistence of Policy Spreads}

\subsection{Fractional Integration}

A fractionally integrated process $y_{t}$ is defined as

$$
(1-L)^{d} y_{t}=x_{t}, \quad t=1, \ldots, T
$$

where $y_{t}$ is a purely stochastic process without deterministic components, $L$ is the lag operator and the fractional differences $(1-L)^{d}$ are given by binomial expansion. If $x_{t}$ is a stationary and invertible ARMA process, then $y_{t}$ is fractionally integrated of order $d$. It is stationary as long as $d<0.5$ and it displays long memory for $d>0$. Long memory implies a form of serial dependence and persistence that cannot be captured by traditional ARMA processes, see Baillie (1996). Specifically, for large lags $h$, the autocorrelation function $\rho_{y}(h)$ of a fractionally integrated process is given by:

$$
\rho_{y}(h) \sim \rho h^{2 d-1} .
$$


It follows that $\rho_{y}(h) \rightarrow 0$ as long as $d<0.5$. However, for $d>0$ the rate of convergence is so slow that the serial correlation coefficients are not summable because of their extremely low decay.

The order of integration $d$ determines the persistence of $y_{t}$. This can be shown by inverting $(1-L)^{d}$ and expanding the ARMA polynomials to obtain the Wold representation in terms of shocks $\varepsilon_{t}$ (with impulse response function $c_{j}$ ):

$$
y_{t}=(1-L)^{-d} x_{t}=\sum_{j=0}^{\infty} c_{j} \varepsilon_{t-j}, \quad \text { with } \quad c_{j} \sim c j^{d-1} .
$$

For $0.5 \leq d<1, y_{t}$ is non-stationary but in contrast to a random walk still mean reverting because the impact of past shocks dies out: $c_{j} \rightarrow 0$. For $0<d<0.5, y_{t}$ is stationary but still exhibits long memory, since shocks die out so slowly that the impulse response function is not summable. Using fractional integration techniques to assess the persistence of policy spreads avoids the rigorous distinction between $\mathrm{I}(0)$ and $\mathrm{I}(1)$ processes and allows for substantially lower decays in the autocorrelation functions. Modeling policy spreads as $\mathrm{I}(0)$ variables when the true data generating process does exhibit long memory may give rise to misleading conclusions regarding its persistence, see Sun (2006).

\subsection{Estimating the Order of Fractional Integration}

The order of integration of $y_{t}$ is determined by semiparametric techniques where $d$ is estimated without specifying or estimating any ARMA components in $x_{t}$, see Eq. (3). Being agnostic about possibly existing shortrun dynamics avoids possible misspecification problems in the estimation. Specifically, the periodogram $I(\lambda)$ is used as the spectral estimator evaluated at frequency $\lambda$. Close to $\lambda=0$, the periodogram is dominated by the order of integration $d$.

The literature proposes various estimation procedures for the order of integration. We employ the local Whittle estimator $\widehat{d}_{L W}$ that minimizes the Whittle function $R(d)$. Following Robinson (1995), the local Whittle estimator has the advantage of being more efficient and more robust than e.g. the log-periodogram estimator introduced by Geweke and Porter-Hudak (1983). It remains consistent for $d$ close to one and is distributed asymptotically normal for $d<0.75$, see Velasco (1999). 
There is an ongoing debate about how to estimate long memory models, see e.g. Baillie and Kapetanios (2008) and Davidson and Sibbertsen (2009). It is therefore worth noting that our main findings seem to be robust with respect to the choice of the semiparametric estimator. In particular, very similar results are obtained for the log-periodogram estimator by Geweke and Porter-Hudak (1983) and the exact local Whittle estimator by Shimotsu and Phillips (2005). The results are also stable with regard to the choice of the bandwidth $m$.

\subsection{The Persistence of Policy Spreads}

Table 2 shows the estimated order of fractional integration for the unadjusted policy spread and the corresponding OIS spread. For all maturities, there is overwhelming evidence that policy spreads exhibit long memory $(\widehat{d}>0)$, see column 1. Adjusting for rate change expectations significantly reduces the persistence of policy spreads. In contrast to the results obtained for unadjusted policy spreads, tests on the order of fractional integration do not reject the stationarity of OIS spreads, see column 2. This indicates that anticipated future policy rate changes drive the order of fractional integration of unadjusted policy spreads artificially above 0.5 .

\subsection{Sensitivity Analysis: Long Memory vs Structural Break}

The current study assesses the controllability of longer-term money market rates by their long-run persistence. It is therefore of crucial importance to ensure that our results regarding the long memory of OIS spreads are not driven by some other nonlinearities.

In our application, the most plausible candidate of a nonlinearity that could have artificially increased the estimated order of integration of OIS spreads are (neglected) shifts in the mean of the time series. Column 3 of Table 2 shows the results from the modified Local Whittle estimator proposed by Hsu (2005) which controls for a single shift in the mean. As expected, the modified estimates of $d$ are smaller than those obtained under the assumption of a constant mean, compare column 2. Yet the differences are negligible in most cases. In fact, according to the test proposed by Hidalgo and Robinson (1996), the estimated mean shifts are typically not signifi- 
Table 2: Fractional Integration of Policy Spreads along the Yield Curve

\begin{tabular}{|c|c|c|c|}
\hline \multirow[b]{2}{*}{$\begin{array}{l}\text { Maturity } \\
(k)\end{array}$} & \multicolumn{3}{|c|}{ Order of Fractional Integration } \\
\hline & $\begin{array}{l}\text { Policy Spread } \\
\quad(r(k)-r *)\end{array}$ & $\begin{array}{c}\text { OIS spread } \\
(r(k)-O I S(k))\end{array}$ & $\begin{array}{c}\text { OIS spread } \\
\text { with mean shift }\end{array}$ \\
\hline $1 \mathrm{w}$ & $\begin{array}{c}0.27 \\
{[0.08]}\end{array}$ & $\begin{array}{c}0.11 \\
{[0.04]}\end{array}$ & {$\left[\begin{array}{l}0.09 \\
{[0.04]}\end{array}\right.$} \\
\hline $2 \mathrm{w}$ & $\begin{array}{c}0.24 \\
{[0.10]}\end{array}$ & {$[0.13$} & $\begin{array}{c}0.08 \\
{[0.06]}\end{array}$ \\
\hline $1 \mathrm{~m}$ & $\begin{array}{l}0.35 \\
{[0.07]}\end{array}$ & {$[0.37$} & {$\left[\begin{array}{c}0.36 \\
{[0.05]}\end{array}\right.$} \\
\hline $2 \mathrm{~m}$ & $\begin{array}{c}0.51 \\
{[0.07]}\end{array}$ & $\begin{array}{c}0.50 \\
{[0.05]}\end{array}$ & {$[0.50$} \\
\hline $3 \mathrm{~m}$ & $\begin{array}{c}0.64 \\
{[0.07]}\end{array}$ & $\begin{array}{c}0.49 \\
{[0.06]}\end{array}$ & {$\left[\begin{array}{c}0.49 \\
{[0.06]}\end{array}\right.$} \\
\hline $4 \mathrm{~m}$ & $\begin{array}{c}0.72 \\
{[0.07]}\end{array}$ & {$\left[\begin{array}{l}0.43 \\
{[0.05]}\end{array}\right.$} & $\begin{array}{c}0.42 \\
{[0.05]}\end{array}$ \\
\hline $5 \mathrm{~m}$ & $\begin{array}{c}0.78 \\
{[0.07]}\end{array}$ & $\begin{array}{c}0.42 \\
{[0.05]}\end{array}$ & $\begin{array}{c}0.41 \\
{[0.05]}\end{array}$ \\
\hline $6 \mathrm{~m}$ & $\begin{array}{c}0.83 \\
{[0.07]}\end{array}$ & $\begin{array}{l}0.45 \\
{[0.05]}\end{array}$ & {$[0.44$} \\
\hline $7 \mathrm{~m}$ & $\begin{array}{l}0.86 \\
{[0.07]}\end{array}$ & {$[0.47$} & {$[0.46$} \\
\hline $8 \mathrm{~m}$ & $\begin{array}{c}0.89 \\
{[0.07]}\end{array}$ & $\begin{array}{l}0.48 \\
{[0.05]}\end{array}$ & {$[0.47$} \\
\hline $9 \mathrm{~m}$ & $\begin{array}{c}0.91 \\
{[0.07]}\end{array}$ & $\begin{array}{l}0.40 \\
{[0.05]}\end{array}$ & $\begin{array}{l}0.39 \\
{[0.05]}\end{array}$ \\
\hline $10 \mathrm{~m}$ & $\begin{array}{c}0.92 \\
{[0.07]}\end{array}$ & {$[0.47$} & {$[0.46$} \\
\hline $11 \mathrm{~m}$ & $\begin{array}{c}0.94 \\
{[0.07]}\end{array}$ & $\begin{array}{c}0.43 \\
{[0.05]}\end{array}$ & {$[0.41$} \\
\hline $12 \mathrm{~m}$ & $\begin{array}{l}0.95 \\
{[0.07]}\end{array}$ & $\begin{array}{c}0.32 \\
{[0.05]}\end{array}$ & $\begin{array}{l}0.30 \\
{[0.05]}\end{array}$ \\
\hline
\end{tabular}

Notes: Sample June 27, 2000 - July 30, 2007. Policy spread $(r(k)-r *)$ between Euribor $(r(k))$ with maturity $k$ and minimum bid rate $(r *)$. OIS Spread $(r(k)-O I S(k))$ between Euribor and corresponding Eonia swap rate. OIS spread with mean shift estimated according to Hsu (2005). The bandwidth $m$ is chosen according to Henry (2001) and Baillie and Kapetanios (2007a). Standard errors Standard errors (in brackets) indicate that for OIS spreads (with or without mean shift) $H_{0}$ : $d \leq 0.5$ cannot be rejected in favor of $H_{1}: d>0.5$ at any conventional significance level.

cant 5 Therefore, the evidence in favor of long memory is very robust to the

\footnotetext{
${ }^{5}$ We do not present these test results for the sake of brevity. Note that tests allowing for more than one break in the mean would lead to similar results. We thank Uwe Hassler
} 
possibility of a mean shift in the time series.

There is no other natural candidate or theoretical prediction regarding a particular form of nonlinearity in the OIS spread series. Detecting some general form of nonlinearity is well beyond the scope of the paper, see e.g. Kuswanto and Sibbertsen (2007). Still, it is worth emphasizing that the Local Whittle estimator applied in this study seems particular robust to various types of nonlinearity, see Baillie and Kapetanios (2007b).

\section{Monetary Policy Implementation and the Persistence of Policy Spreads}

In March 2004, the ECB changed its operational framework to enhance the communication and the effectiveness of monetary policy. Under the new framework, the maturity of the main refinancing operations (MRO) had been reduced from two weeks to one week and an alignment of the reserve maintenance periods, MROs and interest rate decisions has eliminated the disturbing impact of anticipated policy rate changes on current money market rates. Moreover, the ECB has improved its communication to the market by providing more detailed information on its liquidity management (European Central Bank, 2004, p.82).

A number of contributions have analyzed the consequences of these institutional changes for the overnight rate. For example, Nautz and Offermanns (2008) show that the volatility of the overnight rate has been reduced significantly under the new framework. Colarossi and Zaghini (2007) find that the ECB's reform even has affected the transmission of overnight rate volatility to longer-term rates. Focusing on the persistence of policy spreads, we investigate the consequences of the ECB's new operational framework from a different perspective. If the persistence of policy spreads can be related to the controllability of interest rates, the improved efficiency of the new framework should have helped to decrease the persistence of OIS spreads.

To investigate the impact of the ECB's new operational framework on the persistence of OIS spreads, we estimate the order of fractional integration for the periods before and after March 2004 separately. Table 3 shows

and Maya Olivares for providing us with the program codes in R, compare Hassler and Olivares (2008). 
Table 3: Fractional Integration of OIS Spreads along the Yield Curve: The Role of the ECB's Operational Framework

\begin{tabular}{|c|c|c|}
\hline \multirow[b]{2}{*}{ Maturity } & \multicolumn{2}{|c|}{ Order of Fractional Integration } \\
\hline & Old Framework & New Framework \\
\hline $1 \mathrm{w}$ & $\begin{array}{l}0.12^{* * *} \\
{[0.05]}\end{array}$ & $\begin{array}{l}0.14^{* * *} \\
{[0.05]}\end{array}$ \\
\hline $2 \mathrm{w}$ & $\begin{array}{l}0.11^{* * *} \\
{[0.08]}\end{array}$ & $\begin{array}{l}0.14^{* * *} \\
{[0.07]}\end{array}$ \\
\hline $1 \mathrm{~m}$ & $\begin{array}{l}0.34^{* * *} \\
{[0.06]}\end{array}$ & $\begin{array}{l}0.43 \\
{[0.09]}\end{array}$ \\
\hline $2 \mathrm{~m}$ & $\begin{array}{l}0.53 \\
{[0.07]}\end{array}$ & $\begin{array}{l}0.38^{* *} \\
{[0.07]}\end{array}$ \\
\hline $3 \mathrm{~m}$ & $\begin{array}{l}0.49 \\
{[0.07]}\end{array}$ & $\begin{array}{l}0.34^{* *} \\
{[0.07]}\end{array}$ \\
\hline $4 \mathrm{~m}$ & $\begin{array}{l}0.43 \\
{[0.07]}\end{array}$ & $\begin{array}{l}0.26^{* * *} \\
{[0.05]}\end{array}$ \\
\hline $5 \mathrm{~m}$ & $\begin{array}{l}0.45 \\
{[0.07]}\end{array}$ & $\begin{array}{l}0.22^{* * *} \\
{[0.05]}\end{array}$ \\
\hline $6 \mathrm{~m}$ & $\begin{array}{l}0.45 \\
{[0.07]}\end{array}$ & $\begin{array}{l}0.20^{* * *} \\
{[0.06]}\end{array}$ \\
\hline $7 \mathrm{~m}$ & $\begin{array}{l}0.49 \\
{[0.07]}\end{array}$ & $\begin{array}{l}0.19^{* * *} \\
{[0.06]}\end{array}$ \\
\hline $8 \mathrm{~m}$ & $\begin{array}{l}0.51 \\
{[0.07]}\end{array}$ & $\begin{array}{l}0.20^{* * *} \\
{[0.06]}\end{array}$ \\
\hline $9 \mathrm{~m}$ & $\begin{array}{l}0.43 \\
{[0.06]}\end{array}$ & $\begin{array}{l}0.22^{* * *} \\
{[0.06]}\end{array}$ \\
\hline $10 \mathrm{~m}$ & $\begin{array}{l}0.49 \\
{[0.06]}\end{array}$ & $\begin{array}{l}0.13^{* * *} \\
{[0.06]}\end{array}$ \\
\hline $11 \mathrm{~m}$ & $\begin{array}{l}0.48 \\
{[0.06]}\end{array}$ & $\begin{array}{l}0.18^{* * *} \\
{[0.06]}\end{array}$ \\
\hline $12 \mathrm{~m}$ & $\begin{array}{l}0.31^{* * *} \\
{[0.06]}\end{array}$ & $\begin{array}{l}0.17^{* * *} \\
{[0.06]}\end{array}$ \\
\hline
\end{tabular}

Notes: Spread between Euribor and corresponding Eonia swap rate (OIS spread) for June 27, 2000 - March 8, 2004 (old framework) and March 9, 2004 - July 30, 2007 (new framework). The bandwidth $m$ for the local Whittle estimation is chosen optimally according to Henry (2001). Standard errors are given in brackets. The null hypothesis of non-stationarity $H_{0}: d \geq 0.5$ is rejected at the $1 \%$ or $5 \%$ significance level $(* * *, * *)$ in favor of the alternative hypothesis of stationarity $H_{1}: d<0.5$.

that the persistence of OIS spreads is strongly affected by the ECB's operational framework and the communication strategy. As expected, the estimated order of integration seems to be reduced under the new framework. Under the old framework, the order of integration of policy spreads with 
longer maturities remains close to $d=0.5$. In particular, non-stationarity $(d \geq 0.5)$ cannot be rejected for most maturities. In contrast, under the new framework policy spreads still exhibit long memory $(d>0)$ but nonstationarity $(d \geq 0.5)$ can be rejected in most cases. An explicit test for a change in the order of fractional integration is provided by e.g. Sibbertsen and Kruse (2009).

The results obtained from the fractional integration analysis confirm the notion that the communication of monetary policy has substantially improved under the new framework. The lower persistence of policy spreads reveals that the controllability of longer-term money market interest rates was enhanced considerably under the ECB's new operational framework.

\section{Concluding Remarks}

The ability of a central bank to influence longer-term money market rates by managing market's expectations about the future interest rate path is of crucial importance for monetary policy being effective. So far, the controllability of market rates has typically been assessed by the mean and the volatility of policy spreads defined as the deviation of the market rate from the central bank's key policy rate. Advancing on e.g. Balduzzi et al. (1998) and Hassler and Nautz (2008), this paper argued that the central bank's control over longer-term rates should also be reflected in the persistence of policy spreads along the yield curve. If policy spreads are highly persistent, the lasting impact of shocks may impede the transparency of policy signals and, thus, the central bank's impact on longer-term rates.

We employed fractional integration techniques to estimate the persistence of policy spreads corresponding to Euribor rates with maturities ranging from 1 week to 12 month. For each maturity, we found that euro area policy spreads exhibit long memory $(d>0)$. This result is confirmed for expectations-adjusted policy spreads (OIS spreads) where the effects of anticipated policy rate changes have been accounted for. Although stationarity $(d \leq 0.5)$ of expectations-adjusted policy spreads cannot be rejected even for longer maturities, the strong evidence in favor of long memory suggests that the ECB's control of longer-term money market rates might be weaker than expected.

The ECB's new operational framework introduced in March 2004, al- 
lowed us to shed more light on the link between the persistence of policy spreads and the transparency and predictability of monetary policy. Our results indicate that the persistence of policy spreads has significantly declined under the new framework. In particular, the non-stationarity of policy spreads $(d \geq 0.5)$ can only be rejected after the ECB's policy reform. Apparently, by decreasing the persistence of policy spreads along the yield curve, the improved operational framework has increased the central bank's impact on longer-term money market interest rates.

Before the recent financial turmoil, OIS spreads were typically small and controllability and persistence of longer-term money market rates seemed not to be of great concern. Since then, however, OIS spreads have increased to record levels of more than 100 basis points. In line with the predictions of our empirical analysis, OIS spreads have been very persistent during the turmoil and central banks experienced great difficulties to bring OIS spreads back to normal size, see e.g. Taylor and Williams (2009).

\section{References}

Baillie, R. (1996). Long memory processes and fractional integration in econometrics, Journal of Econometrics 73(1): 5-59.

Baillie, R. and Kapetanios, G. (2007a). Semi parametric estimation of long memory: The holy grail or a poisoned chalice? Discussion Paper.

Baillie, R. and Kapetanios, G. (2007b). Testing for neglected nonlinearity in long-memory models, Journal of Business and Economic Statistics 25(4): 447-461.

Baillie, R. and Kapetanios, G. (2008). Nonlinear models for strongly dependent processes with financial applications, Journal of Econometrics 147(1): $60-71$.

Balduzzi, P., Bertola, G., Foresi, S. and Klapper, L. (1998). Interest rate targeting and the dynamics of short-term rates, Journal of Money, Credit and Banking 30(1): 26-50. 
Cassola, N. (2007). Structural modeling of the spread between the Eonia swap rate and the minimum bid rate of the main refinancing operations of the eurosystem. European Central Bank, mimeo.

Cassola, N. and Morana, C. (2008). Modeling short-term interest rate spreads in the euro money market, International Journal of Central Banking 4(4): 1-37.

Colarossi, S. and Zaghini, A. (2007). Gradualism, transparency and improved operational framework: A look at the overnight volatility transmission. CFS Working Paper No. 2007/16.

Davidson, J. and Sibbertsen, P. (2009). Tests of bias in log-periodogram regression, Economics Letters 102(2): 83-86.

Durré, A. (2007). The liquidity premium in the money market: A comparison of the german mark period and the euro area, German Economic Review 7(2): 163-187.

European Central Bank (2004). Monetary policy operations, foreign exchange operations and investment activities, Annual Report, ECB.

Geweke, J. and Porter-Hudak, S. (1983). The estimation and application of long memory time series models, Journal of Time Series Analysis 4(4): $221-238$.

Gil-Alana, L. (2002). Structural breaks and fractional integration in the US output and unemployment rate, Economics Letters 77(1): 79-84.

Hassler, U. and Nautz, D. (2008). On the persistence of the Eonia spread, Economics Letters 101(3): 184-187.

Hassler, U. and Olivares, M. (2008). Long memory and structural change: New evidence from German stock market returns. Goethe University Frankfurt, discussion paper.

Henry, M. (2001). Robust automatic bandwidth for long memory, Journal of Time Series Analysis 22(3): 293-316.

Hidalgo, J. and Robinson, P. (1996). Testing for structural change in a long-memory environment, Journal of Econometrics 70(1): 159-174. 
Hsu, C. (2005). Long memory or structural changes: An empirical examination on inflation rates, Economics Letters 88(2): 289-294.

Kumar, M. and Okimoto, T. (2007). Dynamics of persistence in international inflation rates, Journal of Money, Credit and Banking 39(6): 1457-1479.

Kuswanto, H. and Sibbertsen, P. (2007). Can we distinguish between common nonlinear time series models and long memory? Leibniz University Hannover, discussion paper.

Nautz, D. and Offermanns, C. (2007). The dynamic relationship between the euro overnight rate, the ECB's policy rate and the term spread, International Journal of Finance and Economics 12(3): 287-300.

Nautz, D. and Offermanns, C. (2008). Volatility transmission in the european money market, North American Journal of Economics and Finance 19(1): 23-39.

Pérez Quirós, G. and Rodríguez Mendizábal, H. (2006). The daily market for funds in europe: What has changed with the EMU, Journal of Money, Credit, and Banking 38(1): 91-118.

Robinson, P. (1995). Gaussian semiparametric estimation of long range dependence, Annals of statistics 23(5): 1630-1661.

Shimotsu, K. and Phillips, P. (2005). Exact local whittle estimation of fractional integration, The Annals of Statistics 33(4): 1890-1933.

Sibbertsen, P. and Kruse, R. (2009). Testing for a breal in persistence under long-range dependencies, Journal of Time Series Analysis forthcoming.

Sun, Y. (2006). Spurious regressions between stationary generalized long memory processes, Economics Letters 90(3): 446-454.

Taylor, J. and Williams, J. (2009). A black swan in the money market, American Economic Journal: Macroeconomics 1(1): 58-83.

Velasco, C. (1999). Non-stationary log-periodogram regression, Journal of Econometrics 91(2): 325-371. 


\section{SFB 649 Discussion Paper Series 2009}

For a complete list of Discussion Papers published by the SFB 649, please visit http://sfb649. wiwi.hu-berlin.de.

001 "Implied Market Price of Weather Risk" by Wolfgang Härdle and Brenda López Cabrera, J anuary 2009.

002 "On the Systemic Nature of Weather Risk" by Guenther Filler, Martin Odening, Ostap Okhrin and Wei Xu, January 2009.

003 "Localized Realized Volatility Modelling" by Ying Chen, Wolfgang Karl Härdle and Uta Pigorsch, January 2009.

004 "New recipes for estimating default intensities" by Alexander Baranovski, Carsten von Lieres and André Wilch, January 2009.

005 "Panel Cointegration Testing in the Presence of a Time Trend" by Bernd Droge and Deniz Dilan Karaman Örsal, January 2009.

006 "Regulatory Risk under Optimal Incentive Regulation" by Roland Strausz, January 2009.

007 "Combination of multivariate volatility forecasts" by Alessandra Amendola and Giuseppe Storti, January 2009.

008 "Mortality modeling: Lee-Carter and the macroeconomy" by Katja Hanewald, January 2009.

009 "Stochastic Population Forecast for Germany and its Consequence for the German Pension System" by Wolfgang Härdle and Alena Mysickova, February 2009.

010 "A Microeconomic Explanation of the EPK Paradox" by Wolfgang Härdle, Volker Krätschmer and Rouslan Moro, February 2009.

011 "Defending Against Speculative Attacks" by Tijmen Daniëls, Henk Jager and Franc Klaassen, February 2009.

012 "On the Existence of the Moments of the Asymptotic Trace Statistic" by Deniz Dilan Karaman Örsal and Bernd Droge, February 2009.

013 "CDO Pricing with Copulae" by Barbara Choros, Wolfgang Härdle and Ostap Okhrin, March 2009.

014 "Properties of Hierarchical Archimedean Copulas" by Ostap Okhrin, Yarema Okhrin and Wolfgang Schmid, March 2009.

015 "Stochastic Mortality, Macroeconomic Risks, and Life Insurer Solvency" by Katja Hanewald, Thomas Post and Helmut Gründl, March 2009.

016 "Men, Women, and the Ballot Woman Suffrage in the United States" by Sebastian Braun and Michael Kvasnicka, March 2009.

017 "The Importance of Two-Sided Heterogeneity for the Cyclicality of Labour Market Dynamics" by Ronald Bachmann and Peggy David, March 2009.

018 "Transparency through Financial Claims with Fingerprints - A Free Market Mechanism for Preventing Mortgage Securitization Induced Financial Crises" by Helmut Gründl and Thomas Post, March 2009.

019 "A Joint Analysis of the KOSPI 200 Option and ODAX Option Markets Dynamics" by Ji Cao, Wolfgang Härdle and Julius Mungo, March 2009.

020 "Putting Up a Good Fight: The Galí-Monacelli Model versus 'The Six Major Puzzles in International Macroeconomics'", by Stefan Ried, April 2009.

021 "Spectral estimation of the fractional order of a Lévy process" by Denis Belomestny, April 2009.

022 "Individual Welfare Gains from Deferred Life-Annuities under Stochastic Lee-Carter Mortality" by Thomas Post, April 2009.

\section{SFB 649, Spandauer Straße 1, D-10178 Berlin http:/ / sfb649.wiwi.hu-berlin.de}




\section{SFB 649 Discussion Paper Series 2009}

For a complete list of Discussion Papers published by the SFB 649, please visit http: //sfb649. wiwi.hu-berlin. de.

023 "Pricing Bermudan options using regression: optimal rates of convergence for lower estimates" by Denis Belomestny, April 2009.

024 "Incorporating the Dynamics of Leverage into Default Prediction" by Gunter Löffler and Alina Maurer, April 2009.

025 "Measuring the effects of geographical distance on stock market correlation" by Stefanie Eckel, Gunter Löffler, Alina Maurer and Volker Schmidt, April 2009.

026 "Regression methods for stochastic control problems and their convergence analysis" by Denis Belomestny, Anastasia Kolodko and J ohn Schoenmakers, May 2009.

027 "Unionisation Structures, Productivity, and Firm Performance" by Sebastian Braun, May 2009.

028 "Optimal Smoothing for a Computationally and Statistically Efficient Single Index Estimator" by Yingcun Xia, Wolfgang Härdle and Oliver Linton, May 2009.

029 "Controllability and Persistence of Money Market Rates along the Yield Curve: Evidence from the Euro Area" by Ulrike Busch and Dieter Nautz, May 2009.

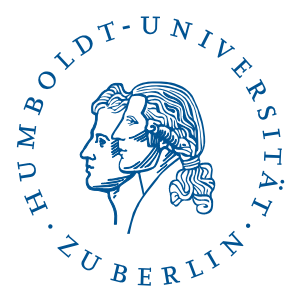

